\title{
Unequal Ideas: Reflections on Designing Politics, an Urban Ideas Competition in Rio de Janeiro Adam Kaasa
}

1 Theatrum Mundi was cofounded by the author, Adam Kaasa, and Richard Sennett in 2011 to investigate the relationship between the city and the visual and performing arts. Based at LSE cities in the London School of Economics in London, UK, and at the Institute for Public Knowledge at New York University, it received a small amount of funding from the National Endowment for Science Technology and the Arts (NESTA) and the Mellon Foundation in 2012 and core funding from a private individual, James Anderson, from 2013 to 2020. In 2017 it established itself as an independent charity in the UK. Designing Politics began with "Designing for Free Speech" in New York (2014) and "Designing the Urban Commons" in London (2015). See http://theatrum-mundi.org and http://designingpolitics.org.

2 Jeremy Till states that "[t]here isn't much written about architectural competitions ... I find them incredibly exploitative from the point of view of labour ... Generally, competitions privilege a certain set of aesthetics and formal devices. ... For me the competition exemplifies a lot of what's wrong about architecture." Adam Wood, "Interview with Jeremy Till on Schools, Contingency, Flexibility and Competitions," Architecture and Education, January 18, 2018, https://architecture andeducation.org/2018/01/18/interviewwith-jeremy-till-on-schools-contingencyflexibility-and-competitions/ (accessed July 8 2018).

3 See specifically Sara Ahmed, Living a Feminist Life (Durham: Duke University Press Books, 2017); and Sara Ahmed, Willful Subjects (Durham: Duke University Press Books, 2014).

4 Sara Ahmed, Willful Subjects (Durham: Duke University Press Books, 2014), 1.

\section{An Unequal Burden}

The "Designing Politics/Designing Respect" (DPDR) urban ideas competition, run by Theatrum Mundi (TM) in Rio de Janeiro in 2016, nearly ended before it even began. ${ }^{1}$ The first research seminar was held in Rio de Janeiro in March 2016 to gauge the interest of prospective collaborators; at this meeting, one curator from a prominent museum looked around the table and asked, "Why partner with Theatrum Mundi or the LSE [London School of Economics]? If we want to do this competition in Rio, we should do it ourselves." In the two previous Designing Politics (DP) competitions, in New York (2014) and London (2015), no one in the organizing teams, the expert juries, or the public raised formal objections or questions about the nature of the competition, the organizations involved (TM, LSE, or New York University [NYU]), or the structure of the competition itself (the submission requirements, the jury, the exhibition). However, the DPDR competition in Rio de Janeiro brought all of these elements into question. In this article, and as co-founder and Director of TM, I use an auto-ethnographic methodology - to understand why. This article, which reports the results of my study, argues for the decolonization of structures like the DPDR competition, which have been central to architectural and design pedagogy and practice. ${ }^{2}$

This article, building on the work of Sara Ahmed, and specifically her notion of the willful subject, initiates a discussion about the unequal geography of labor and challenges institutions and processes of public scholarship in design. ${ }^{3}$ Ahmed writes that "willfulness is a diagnosis of the failure to comply with those whose authority is given." ${ }^{\prime 4}$ The comparison between the urban competitions in New York, London, and Rio de Janeiro demonstrates that it was only in the Global South that challenges to the technology of the competition were raised. These challenges were based on issues of power imbalances between institutions both within and between the Global North and the Global South, and 
$5 \quad$ These challenges were raised multiple times, both by initial partners in the United Kingdom (People's Palace Projects) in December 2015 and at the first meeting with collaborators in Rio de Janeiro in March 2016

6 For a detailed examination of the DPDR competition in relation to broader processes of neoliberal transformation in Rio de Janeiro, see Laura Burocco, “Designing Politics: Designing Respect: poder e alteridades dentro de parcerias cultuais internacionais," [Designing Politics: Designing Respect: power and alterities within international cultural partnerships] Ciências Sociais Unisinos 53, no. 3 (September 27, 2017): 400-12. Burocco specifically examines the urban regeneration of the Port of Rio through two major iconic museum infrastructure projects, the Museu do Amanhã and the Museu de Arte do Rio - both of which were early partners for DPDR.

7 Extensive scholarship has examined the relationship between the competition, architecture and urban planning, and colonialism. See, e.g., Itohan Osayimwese, Colonialism and Modern Architecture in Germany (Pittsburgh, PA: University of Pittsburgh Press, 2017); Esra Akcan and Sibel Bozdogan, Turkey: Modern Architectures in History (London: Reaktion Books, 2011); Patricia A. Morton, Hybrid Modernities: Architecture and Representation at the 1931 Colonial Exposition, Paris (Cambridge, MA: MIT Press, 2003); and James Holston, The Modernist City: An Anthropological Critique of Brasilia: Architecture, Politics and Society in Brasilia (Chicago: University Of Chicago Press, 1989). around questions of the social inequalities embedded in the structures of the competition itself (i.e., the submissions, the jury, and the exhibition). ${ }^{5}$ Through this analysis, I suggest that the burden of the labor of decolonizing rests on those already oppressed by systems embedded in the continuous presence of coloniality. Those who labor on decolonization are often, as will be shown in the case of the DPDR, produced by power as willful subjects, as problems defying the status quo.

Specifically, I analyze the questions raised by collaborators based in Rio de Janeiro about who the local competition partners might be, about the entry requirements, about the jurying process, and about the exhibition. This article demonstrates that these questions about the seemingly technocratic methodology of the competition brought about small changes that altered the competition significantly from its previous iterations in New York and London. However, I argue that the competition remained deeply ingrained in institutions that have yet to undergo any serious process of decolonization. Indeed, some of these institutions are having the opposite effect, furthering racial and economic urban inequality in Rio de Janeiro through contributions to broader neoliberal urban restructuring. ${ }^{6} \mathrm{TM}$ did not thoroughly research the very nature of an ideas competition, nor did it historicize the competition in terms of planning and design history and its colonial roots. ${ }^{7}$ Examining the DPDR urban ideas challenge offers the opportunity to reflect on the complexity of working toward decolonization within institutions that are rooted in colonial practices of knowledge production, while underscoring the inequality rooted in the burden of labor to push for such change.

The DP project as a whole had two core purposes: 1) to test the limits of addressing political questions through design; and 2) to be a testing ground for interdisciplinary work. Given the base of TM in both New York and London, the project began with an annual competition in each of these cities. In each case, a briefmodeled on architectural competitions-was written in relation to a political question specific to the city in which it took place and emerging from discussions organized by TM. An open call through established networks invited responses to the brief. A jurying process identified winners, and an exhibition displayed and disseminated them. Most readers likely are familiar with this process because, as a repeated model, it operates as a particular way of structuring knowledge. In the remainder of the article, I reflect on the shifts in the competition over three years, specifically focusing on the changes in the Rio de Janeiro competition. I end with a critique of ongoing institutional structures that produce unequal ideas in design pedagogy and practice. 


\section{The Structure of the Competitions}

The structure of the DP competition mirrored that of an architectural competition: It included an open call to participate through professional or partnered channels; a defined set of entry requirements; a jurying process; and an exhibition. One of the critiques from decolonial scholarship is that it is not enough to diversify or make more accessible existing structures of knowledge production, but to challenge the structures of knowledge production themselves. ${ }^{8}$ In the case of an urban ideas competition, opening up participation is one thing; developing a critique of the kinds of knowledge that are being produced by it, and of the circulation of power that it enables, is quite another. In New York and London, the conditions of participation, jury, and exhibition were given little consideration; meanwhile, in Rio de Janeiro, these issues were points of discussion with partners in that city from the very beginning. Although changes were made to shift certain elements of the competition in Rio de Janeiro, the structure of the competition itself, as a form of knowledge production, remained unchanged. In what follows, I compare the network, submissions, jury, and exhibitions to demonstrate the shift made between the New York, London, and Rio de Janeiro competitions, and I discuss their effects.

\section{Networks}

In New York and in London, the competitions relied on TM's existing networks for the open call and for the culminating exhibition. They relied heavily on relationships with other universities, architectural schools, and established art and cultural organizations in the city. In New York, the American Institute of Architects hosted the final competition exhibition (a small set of A3 printouts of the ten winners); in London, the LSE's TM, the competition organizer, hosted a much larger curated public exhibition of the competition winners during the London Festival of Architecture in June and July 2015. A second smaller exhibition was held during the MakeCity: Berlin Festival, also in June 2015. In addition, in London, three large public lectures were organized throughout the ideas competition to further expand a public conversation. These lectures remained within the structure of the university's organized public events and publics. ${ }^{9}$

In Rio de Janeiro, the core partnership of the program was between TM and People's Palace Projects (PPP), a collaboration with Queen Mary University in London and Casa Rio in the neighborhood of Botofogo. Although this partnership arose through an existing TM relationship in London, PPP raised the question early on as to whether the project would target traditional university and architectural school routes or include alternative educational partners. Opting for the later, we partnered with Spectaculu, an art and technology school for low-income youth across the city. This http://designingtheurbancommons.org/ events/ (accessed July 8 2018). 
10 Burocco, "Designing Politics," 402-06.

11 See Tulio Tavares, "Sobre Museus e Monstros," [About museums and monsters] NaBorda, August 9, 2017, http:// www.naborda.com.br/2017/08/09/sobremuseus-e-monstros/ laccessed June 8, 2018); Luana Bulcão, “Museu Do Amanhã: A Cultura Como Ícone Do Planejamento Estratégico, Barbárie Ou Civilização Na Construção Do Amanhã?," [Museum of Tomorrow: Culture as an icon of strategic planning, barbarism or civilization in the construction of tomorrow?] Intercom - Sociedade Brasileira de Estudos Interdisciplinares Da Comunicação, September 9, 2017 , http://portalintercom.org.br/anais/ nacional2017/resumos/R12-0689-1.pdf (accessed June 8 2018); Flora d'El Rei Lopes Passos, “0 Espetáculo Dos Espaços Públicos: Vivências E Expressões Culturais Na Zona Portuária Do Rio de Janeiro," [The spectacle of public spaces: experiences and cultural expressions in the port zone of Rio de Janeiro] Revista Brasileira de Estudos Urbanos E Regionais 16, no. 2 (November 2014): 81-96.

12 The diversification of publics might be an appropriate outcome of processes pursuing "equality" of access to spaces of knowledge production, such as the museum or the university; however, such diversification is not the same as decolonizing these same institutions, such that an epistemological decolonization might occur. For example, J'net AyAyOwaYakSheelth argues in the Canadian perspective that decolonization is not just about getting diverse people through the museum door; instead, it must include "[i]ndigenous professional learning to become mandatory and ongoing for museum professionals and volunteers within every department of our public institutions." See Wendy $\mathrm{Ng}$ and J'net AyAyOwaYakSheelth, "Decolonize and Indigenize: A Reflective Dialogue," Viewfinder: Reflecting on Museum Education, June 12, 2018 , https://medium.com/viewfinder-reflecting-on-museum-education/decolonizeand-indigenize-a-reflective-dialogue3de78fa76442 (accessed June 22, 2018) Similarly, Linda Tuhiwai Smith argues that "[d]ecolonization, once viewed as the formal process of handing over the instruments of government, is now small shift in orientation altered the project in a few ways. First, we decided to expand the competition to include a second internal competition for the students at Spectaculu. A day-long workshop with students produced a high entry rate from the school. Three internal student-winners were offered the additional prize of a trip to Paris and London to participate in cross-cultural learning and exchange. Second, although countless public lectures were delivered in Rio de Janeiro and in São Paulo at universities, at colleges, and at design, culture, and activist organizations, the institutional affiliation did not rely on a university-to-university exchange. Given the intersectional barriers to entry to university education, this shift seemed important in making the competition, if not more public, at least engaged with and addressing different publics.

In terms of the partners for the exhibition, the competition was launched in June 2016 at the Museu de Arte do Rio and was exhibited in October 2016 at the Museu da Amanhã. Both of these institutions are new and very controversial developments in Rio de Janeiro. ${ }^{10}$ However, whereas the exhibition took place in New York in a professional center for architecture, and in London at an elite university, in Rio de Janeiro it took place at one of the most popular museums in the country. The relationship of these museums to infrastructural reorganization of the city, to financial speculation, and to urban gentrification have been well researched ${ }^{11}$; deciding to partner with a public institution like a museum oriented the dissemination to a very different public than previous competitions had. ${ }^{12}$

\section{Entry Requirements}

To participate in the DP ideas competitions in New York, TM asked for three elements: 1) to identify a space in New York for the intervention (250 words and up to five images); 2 ) to design the physical or performative intervention ( 250 words and up to five visual elements, such as designs, sketches, or photos); and 3) to describe its implementation ( 250 words). Following the jurying process, winning teams were given the opportunity to resubmit another designed board for exhibition..$^{13}$ In London, the entry requirements were changed. To enter in London, teams were required to submit: 1) an A0 board in landscape format; 2) a 300-word rationale; 3 ) a headline image cropped to 900px; and 4) an optional video of up to three minutes. ${ }^{14}$ Making entry requirements specific ensured a consistency of submissions that was easy to coordinate for the jurying process and simple to assemble into an exhibition.

Each of these submission requirements involves embedded biases that produce social inequality. To produce an A0 board, or to crop an image to $900 \mathrm{px}$, teams would need to have a computer, to have design software, to have significant design education, or to have networks with this kind of access or expertise. In New York 

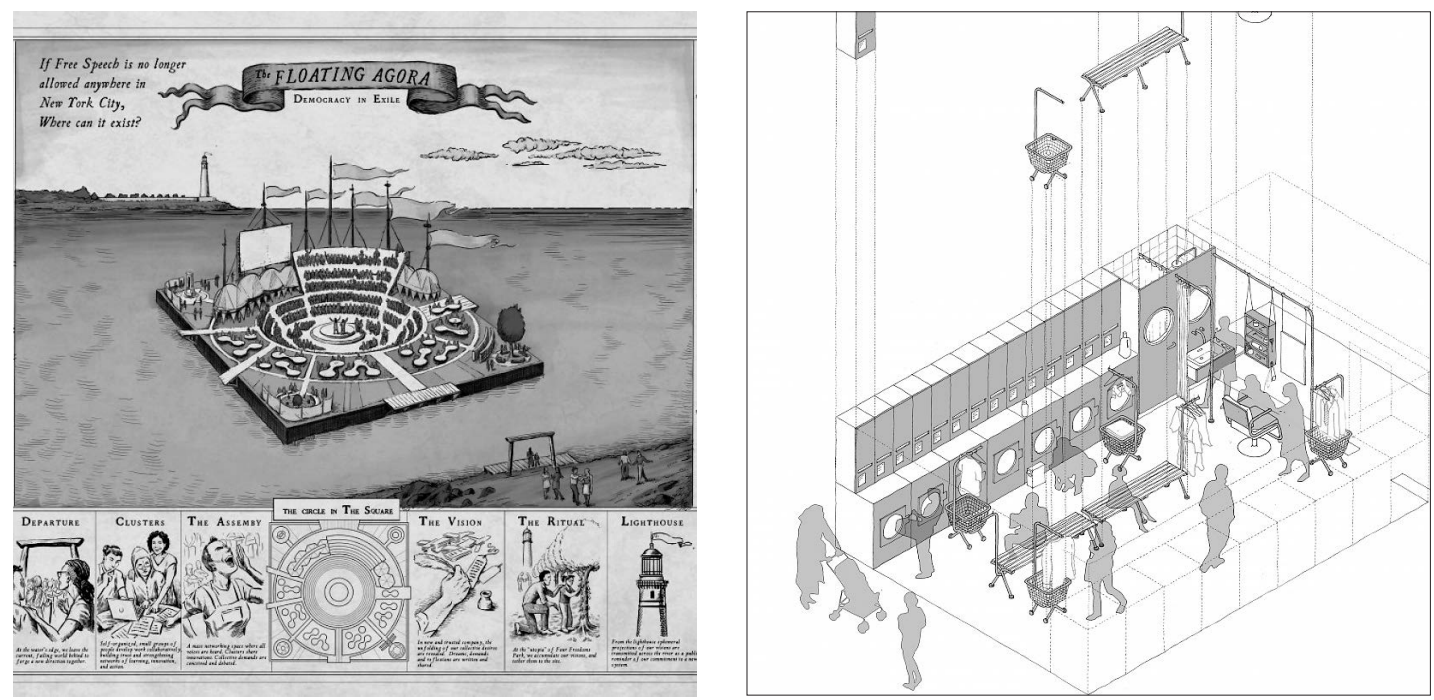

Figure 1 (left)

Floating Agora by Raquel de Anda, Gan Golan, and Ron Morrison. Jury winner for the New York "Designing for Free Speech" competition in 2014. Source: Theatrum Mundi.

Figure 2 (right)

Service Wash by Alpa Depani and Thomas Randall-Page. Public voting winner for the London "Designing the Urban Commons" competition in 2015. Source: Theatrum Mundi, www.thomasrandallpage.com and www.alpadepani.com.

recognized as a long-term process involving the bureaucratic, cultural, linguistic, and psychological divesting of colonial power. See Linda Tuhiwai Smith, Decolonizing Methodologies: Research and Indigenous Peoples (London: Zed Books, 2012), 98. See also Ramón Grosfoguel, "The Epistemic Decolonial Turn," Cultural Studies 21, no. 2-3 (March 1, 2007): 211-23.

13 See full details for the entry for the New York competition here: http:// designingpolitics.org/designing-forfree-speech/challenge/ laccessed June 22, 2018).

14 See full details for the entry for the London competition here: http:// designingpolitics.org/designing-theurban-commons/challenge/ (accessed June 22, 2018).

15 See full details for the entry for the Rio de Janeiro competition here: http:// designingpolitics.org/designing-respect/ detalhes/ (accessed June 22, 2018). and London, decisions about entry requirements were made without considering the barriers to entry they represented; however, in Rio de Janeiro, these barriers were one of the first issues discussed with jury members and Rio-based collaborators. These discussions occurred in March 2016, even before the decision to go ahead with the competition was made. In Rio de Janeiro, TM made the decision to try and make the competition accessible to anyone with, or with access to, a mobile phone. The entry requirements in Rio were the following: 1) up to 5 images (e.g., snapshots, hand drawings, or designs, without preference for design expertise); 2) up to 300 words of text describing the idea; and 3) up to three minutes of video or audio as an online link. ${ }^{15}$

The resulting entries in Rio de Janeiro were significantly different from previous competitions. In New York and London, the entries were overwhelmingly produced by architecture and design experts who clearly had experience and education in visual design and access to hardware and software to enhance their entries (see Figures 1 and 2). In Rio de Janeiro, many submissions for the visual element of the entries were photographs, many were hand-drawn images later snapped by a mobile phone (see Figure 3 ), and the few heavily designed entries came from people active in higher education (e.g., professors and PhD students) or from those in the architectural or design disciplines, as evidenced by their accompanying biographies. In London and New York, we saw a greater consistency with regard to the design language of the entries, while in Rio de Janeiro, we saw a very wide range of knowledges and expertise. On reflection, the consistency in London and New York might have had little to do with the quality of ideas in these cities, and more to do with the institutional positioning of the competition within networks of formal design expertise. 
Figure 3

Favela Barroca by Katianne Berquiolli, Lecticia Barros, Valdemar Candido Vargas, and Hyan Victor Costa Cantanhede. Spectaculu-selected winner for the Rio de Janeiro "Designing Respect" competition in 2016. Source: Theatrum Mundi.

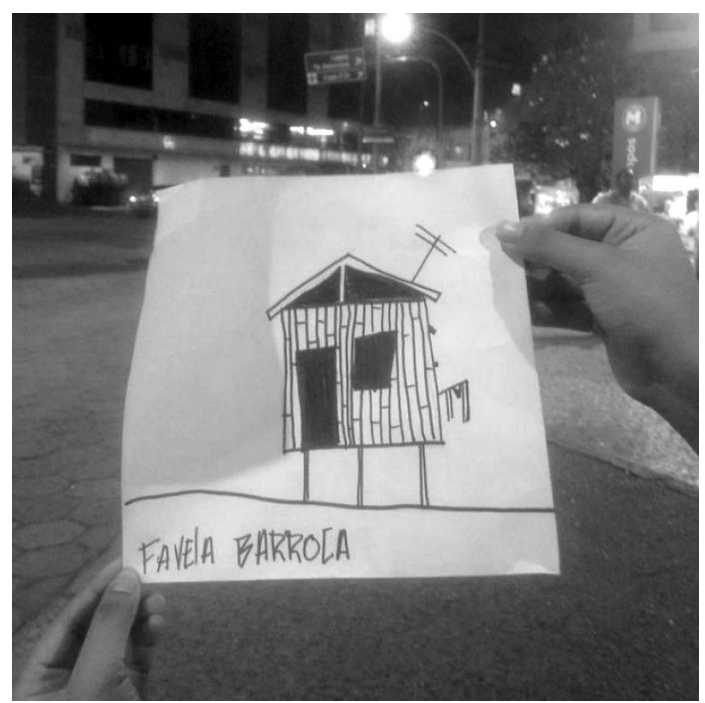

The diversity of entrants in Rio de Janeiro created a hierarchy of "unequal ideas" based on aesthetic recognition, rather than on the merit or innovation of the idea itself. Senior members of the TM governing team commented that a number of the entries seemed "naive," and they questioned the validity of the competition in Rio de Janeiro, compared with the "sophistication" of the entries from New York and London. The comments were based largely on visual cues, such as a comparison of a hand-drawn entry sketch from someone without a professional art background, to a heavily designed A0 board from professional architects in London. Although the ideas might have similar merit, the structural aesthetics of what was considered to be appropriate display of knowledge and expertise was made visible through these senior members' comments. This discussion about the shift in the entry requirements makes visible the structural barriers to participation in competitions like these. Significantly, when barriers were lifted so that participants might have more and different forms of expertise, the boundaries indicating appropriate or "sophisticated" ideas were policed by those who judged some of the entries as naive.

\section{The Jury}

In most architectural competitions, the jury meets behind closed doors and produces long lists, short lists, and winners. Although each of the DP competitions had expert juries made up of professionals from the urban and cultural sectors, we also made an effort to include the public. In New York and London, an expert jury chose eight of ten winners, and a public vote online chose the remaining two. Because those who chose to participate in the public voting process came from existing networks, we assumed that the ones taking the time to look through the entries and to vote for 
the public' winners were largely the entrants themselves and their networks of friends and colleagues. At the New York and London exhibitions, then, the winners decided by the expert jury and the winners decided by the public were identified as such, marking out the difference between them. In Rio de Janeiro, an expert jury was assembled for the competition; however, after the competition closed and the jury met to decide the winners, the jury members made a unanimous decision to democratize the jurying process. The jury itself was not content to remain within the black-box of expertise. Thus, a peer jury was created whereby every team that entered would put forward its selection for the top ten ideas (but could not include its own work). The change to the jurying process happened during the competition itself, and it gave responsibility for choosing the winning ideas to those who had contributed collective labor in producing the ideas. This jurying, then, was not a public vote, but rather an expansion of the competition to include adjudicating on the entries.

This decision produced frustration among some of the entrants. The main challenges came from entrants from universities and from those who had professional backgrounds. One professional entrant initially refused to vote for the top ten, arguing that there were not ten worthy ideas. Another thought they were going to be disadvantaged because the networks of other entrants (e.g., from neighborhood cultural organizations, or from schools or training centers specifically targeting students from low-income neighborhoods) were stronger and larger and would vote as a block. These reactions sent via email to the organizers, although anecdotal in nature, point again to a sense of the inequality of ideas in two ways. First, they suggest that the ideas submitted were not complex enough to qualify as high quality, perhaps within a hierarchy of value that privileges professional and academic knowledge production. Second, they conveyed condescension toward entrants who presumably would vote only along identitarian or networked lines and not for the best ideas. The implied accusation that students and colleagues from a particular school or organization might vote for each other's entries, rather than consider all the ideas and put forward the ones they thought were best makes visible a kind of reverse-privilege argument. When those from a disadvantaged background assert a presence, it is seen as a claim or, in Ahmed's terms, a kind of "willful subject." Whether opening the jury process to a "peer jury" made the jurying process more fair (if any jurying process is, indeed, fair) is difficult to discern; what the reactions to it demonstrate is the persistence of the idea that aesthetic value and intellectual heft are tied to existing institutional structures of power: to the university-educated and those with design aesthetic backgrounds. In short, it made clear the structures from which certain ideas become framed as more equal than others. 


\section{The Exhibition}

A final difference between the earlier competitions of New York and London and the one in Rio de Janeiro rests in what was officially exhibited. In New York, it consisted of a small exhibition of A3 prints of the winners in the back room of the American Institute of Architects. In London, the London Festival of Architecture co-organized a larger, month-long exhibition with LSE Arts at the LSE. The exhibition was designed for and showed the winning A0 board submissions and rationale text; it also included a short description of the winning projects in New York, for continuity, and a wooden-block map of the locations in London of the winners. In both New York and London, the full set of entries was rotating on screen projection, and all the entries continue to be publicly available as an archive online.

In Rio de Janeiro, when the jury made the decision to use a peer jury system, it also decided to exhibit all the entries, and not just the winners. The exhibition therefore included the peer jury winning entries, the full set of all entries (curated along thematic lines), a separate set of the three winners of the Spectaculu internal competition, a map identifying all the entries, and iPads to preview the entries online, including all images, text, video, and audio. Although the previous exhibitions displayed a strong hierarchy of project ideas, in Rio de Janeiro, all the entries were represented and acknowledged. The inclusive nature of the exhibition meant that one of the non-winning entries, which was performance-based and confronted issues of gender, sexuality, and race, became the focus of a national television program.

The structure of a traditional ideas competition creates a structure of (unequal?) reciprocity, where unpaid labor to produce entries is offset by the possibility of "winning," of being raised up in importance through the structural inequality of an expert jury and a closed curatorial process. Here, as the jury system shifted to a more democratic process, a more inclusive exhibition also gave visibility to the labor behind all the ideas.

\section{Being Undone But Not Undoing}

This article ends where it began: on the final day of a five-day scoping visit to Rio de Janeiro in March 2016-fall in the southern hemisphere. I sat in a roundtable of cultural leaders, journalists, activists, politicians, artists, and urbanists to discuss the possibility of holding this public urban ideas competition. Conducted in Portuguese, the roundtable held onto the competition as a possibility, and not as a fait-accompli. Together, my new colleagues in Rio de Janeiro asked, "if we're interested in this ideas competition, why don't we do it ourselves? Do we need to partner with TM or with the LSE?" The iteration of DPDR in Rio de Janeiro began as a process of having "been undone," to use Irit Rogoff's words—that is, 
16 Irit Rogoff, "From Criticism to Critique to Criticality," Transversal Texts (2003), http://transversal.at/transversal/0806/ rogoff1/en?highlight=rogoff (accessed March 3, 2018).

17 See Ahmed, Living a Feminist Life, 1-18.

18 For an excellent institutional critique of the DPDR competition in Rio, see Burocco, "Designing Politics," 400-12.

19 Julietta Singh argues, however, that expertise or "mastery" is itself a structure of knowledge embedded in the history and ongoing power structures of colonization. See Unthinking Mastery: Dehumanism and Decolonial Entanglements (London: Duke University Press, 2018).

20 Adelia Miglievich-Ribeiro, and Edison Romera. "Orientações Para Uma Descolonização Do Conhecimento: Um Diálogo Entre Darcy Ribeiro E Enrique Dussel [Guidelines for a Decolonization of Knowledge: A Dialogue Between Darcy Ribeiro and Enrique Dussel], Sociologias 20, no. 47 (April 2018): $108-37$. with the question on the table as to whether to continue with the project at all. ${ }^{16}$ The process of undoing is, perhaps, similar to Walter Mignolo's notion of "delinking," in a decolonial sense. The a priori knowledge conditions of power and expertise in modernity must be detached from the seemingly naturalized institutions-like the university — and from techniques and technologies - like the ideas competition. Resistance must counter the assumption that the production of knowledge is neutral and that the diversification of its content or actors is sufficient. Rather, structures like a competition, so central to architectural and urban design pedagogy and practice, need to be rigorously interrogated.

All the changes that took place for DPDR in Rio de Janeiro with regard to the network, the entry requirements, the jury process, and the exhibition came through direct confrontation, debate, criticism, and dialogue with partners and colleagues from that city. Part of the reflection I want to offer is that the people we worked with in Rio de Janeiro are the ones who bore the burden of labor to make visible the embedded systems of inequality within a design competition. Although New York and London are cities of extreme social and spatial inequality, they did not undertake the labor or bear the burden of changing perceptions.

At times, senior colleagues at my institution found this criticism of the competition unwarranted-as a laborious antagonism. This reaction makes me think of Ahmed's "feminist killjoy," the subject who halts or interrupts the status quo, and therefore interrupts the ease of the processes that contribute to systemic reproductions of power. ${ }^{17}$ On reflection, it became clear how inaccessible the DP competitions in New York and London were, and the specific kinds of knowledge they produced. Shifting the conditions of the competition slightly did not shift the structural, institutional, financial, governmental, or geographic inequalities that make up international competitions such as these. ${ }^{18}$ This reflection on the DPDR ideas competition in Rio de Janeiro suggests that the very techniques meant to open up participation from a broad public, an open-call design challenge, free and open to all, conditions the possibility of participation and might reproduce systemic inequalities through its very structure. I do not want to suggest that design expertise is antithetical to a project of decolonization..$^{19}$ Rather, what is at stake is what is counted as design expertise; what must be perceived is the neo-colonialisms embedded in the present that perpetuate hierarchies of knowledge production, and in perceiving them, working to change them. ${ }^{20}$ 